\title{
Thermal Decomposition of Cellulose/Synthetic Polymer Blends Containing Grafted Products IV. Cellulose/Poly(2-hydroxyethyl methacrylate) Blends
}

\author{
Noboru NishioKa, ${ }^{\dagger}$ Takeshi ITOH, and Masakuni UNO* \\ Department of Materials Science, Osaka Electro-Communication University, \\ Neyagawa, Osaka 572-8530, Japan \\ * Junior College Division, Osaka Electro-Communication University, \\ Neyagawa, Osaka 572-8530, Japan
}

(Received April 5, 1999)

\begin{abstract}
Homogeneous grafting of 2-hydroxyethyl methacrylate onto cellulose was carried out in a dimethyl sulfoxide/paraformaldehyde solvent system. The grafted products were added to cellulose/poly(2-hydroxyethyl methacrylate) (PHEMA) blends as compatibilizers. The thermal decomposition behavior of the blends was investigated by thermogravimetry. The thermal stability of the blends decreased with an increase in grafted product content. Peak intensity of wide-angle X-ray diffraction patterns decreased with grafted product content. The microphase-separated structures of the blends became finer with grafted product content. Dynamic mechanical measurements were carried out to determine glass transition temperatures, $T_{\mathrm{g}}$, of the blends. $T_{\mathrm{g}}$ for cellulose decreased with grafted product content but that for PHEMA increased. Differences in thermal decomposition behavior of the blends were correlated to compatibility. Thermogravimetry was effective for compatibility estimation in cellulose/PHEMA blends containing grafted products.
\end{abstract}

KEY WORDS Thermal Decomposition / Cellulosic Blend / Grafted Product / Compatibilizer /

In our previous work, ${ }^{1,2}$ the thermal decomposition behavior of vinyl monomer grafted cellulose products was investigated by thermogravimetry. The thermal stability of grafted products with higher graft copolymer content decreased remarkably. The grafted products are considered polymer blends consisting of cellulose, attendant synthetic homopolymers, and graft copolymers as compatibilizers. The thermal stability of the grafted products with good compatibility decreased markedly. Compatibility in polymer blends can be estimated from glass transition temperatures, $T_{\mathrm{g}}{ }^{3-5}$ However, cellulose does not undergo a clear glass transition. Variation in thermal decomposition behavior of cellulosic blends should be correlated more precisely with that in compatibility to make thermogravimetry effective for compatibility estimation in cellulosic blends.

In subsequent work, ${ }^{6-8}$ we added grafted products to cellulose(Cell)/synthetic polymer blends as compatibilizers to vary graft copolymer content widely. The thermal decomposition behavior of the blends was correlated to compatibility. In this work, 2-hydroxyethyl methacrylate(HEMA) grafted cellulose products were added to Cell/poly(2-hydroxyethyl methacrylate) (PHEMA) blends. PHEMA containing hydroxyl groups is able to interact with cellulose. The thermal decomposition behavior of Cell/PHEMA blends likely differs from that of other cellulosic blends investigated. ${ }^{6-8}$

\section{EXPERIMENTAL}

\section{Grafting and Sample Preparation}

Homogeneous grafting of HEMA onto cellulose in a dimethyl sulfoxide (DMSO)/paraformaldehyde (PF) solvent system and characterization of the grafted products were performed as described previously. ${ }^{9-12}$

† To whom correspondence should be addressed.
The grafted products are characterized in Table I. In homogeneous grafting, the molecular weight of the graft polymer is presumed equal to that of the attendant homopolymer. ${ }^{13,14}$ Viscosity-average molecular weights, $M_{v}$, of the extracted PHEMA thus were used as those of the graft polymers. The values of $M_{v}$ of cellulose and PHEMA used for the blends were estimated to be $146 \times 10^{3}$ and $220 \times 10^{3}$ from intrinsic viscosity obtained with cadoxen ${ }^{15}$ at $20^{\circ} \mathrm{C}$ and $N, N$-dimethylformamide ${ }^{16}$ at $30^{\circ} \mathrm{C}$, respectively.

Crude reaction mixtures, DMSO/PF solution of cellulose, and DMSO solution of PHEMA were mixed to give proper blend ratios. The mixtures were cast onto glass plates at room temperature and dried at about $40^{\circ} \mathrm{C}$ under reduced pressure for $24 \mathrm{~h}$. After being immersed in water for several days, the films were easily peeled off, air dried on filter papers at room temperature, and stored in a desiccator until use.

\section{Measurements}

A SEIKO SSC5000TA with a TG/DTA300 module was used for thermal decomposition measurement. The samples $(\mathrm{ca} .15 \mathrm{mg})$ were preheated to $150^{\circ} \mathrm{C}$ at a heating rate of $10^{\circ} \mathrm{C} \mathrm{min}^{-1}$ under nitrogen flow at $100 \mathrm{~mL} \mathrm{~min}^{-1}$ to evaporate adsorbed water. Measurement was carried out from room temperature to $600^{\circ} \mathrm{C}$ under the above conditions.

Wide angle X-ray diffraction profiles were obtained for film specimens using a Shimadzu XD-3A diffractometer.

A Hitachi HU-11A transmission electron microscope (TEM) was used to observe microphase-separated structures. The samples were stained with osmic acid vapor for $24 \mathrm{~h}$. The copolymer of $n$-butyl methacrylate and methyl methacrylate was used as the embedding medium. The embedded samples were cut into ultrathin sections of $50 \mathrm{~nm}$ thickness. 
Thermal Decomposition of Cellulose/PHEMA Blends

Table I. Characterization of grafted products ${ }^{\mathrm{a}}$

\begin{tabular}{|c|c|c|c|c|c|}
\hline \multirow{2}{*}{ Sample code } & \multicolumn{3}{|c|}{ PHEMA content $/ \mathrm{wt} \%$} & \multirow{2}{*}{$\begin{array}{c}M_{v} \times 10^{-3} \\
\text { of } \mathrm{graft}^{\mathrm{b}}\end{array}$} & \multirow{2}{*}{$\begin{array}{l}\text { Number } \\
\text { of grafts }\end{array}$} \\
\hline & Overall & Graft polymer & Homopolymer & & \\
\hline g-PHEMA01 & 10.7 & 3.6 & 7.1 & 78 & 0.07 \\
\hline g-PHEMA02 & 9.2 & 3.4 & 5.8 & 44 & 0.13 \\
\hline g-PHEMA03 & 13.6 & 6.9 & 6.7 & 105 & 0.11 \\
\hline g-PHEMA04 & 15.6 & 4.6 & 11.0 & 50 & 0.16 \\
\hline
\end{tabular}

${ }^{\mathrm{a}}$ Viscosity-average molecular weight $\left(M_{v}\right)$ of main chain cellulose is $146 \times 10^{3} .{ }^{\mathrm{b}} M_{v}$ of the extracted PHEMA homopolymer was used as that of the graft polymer.
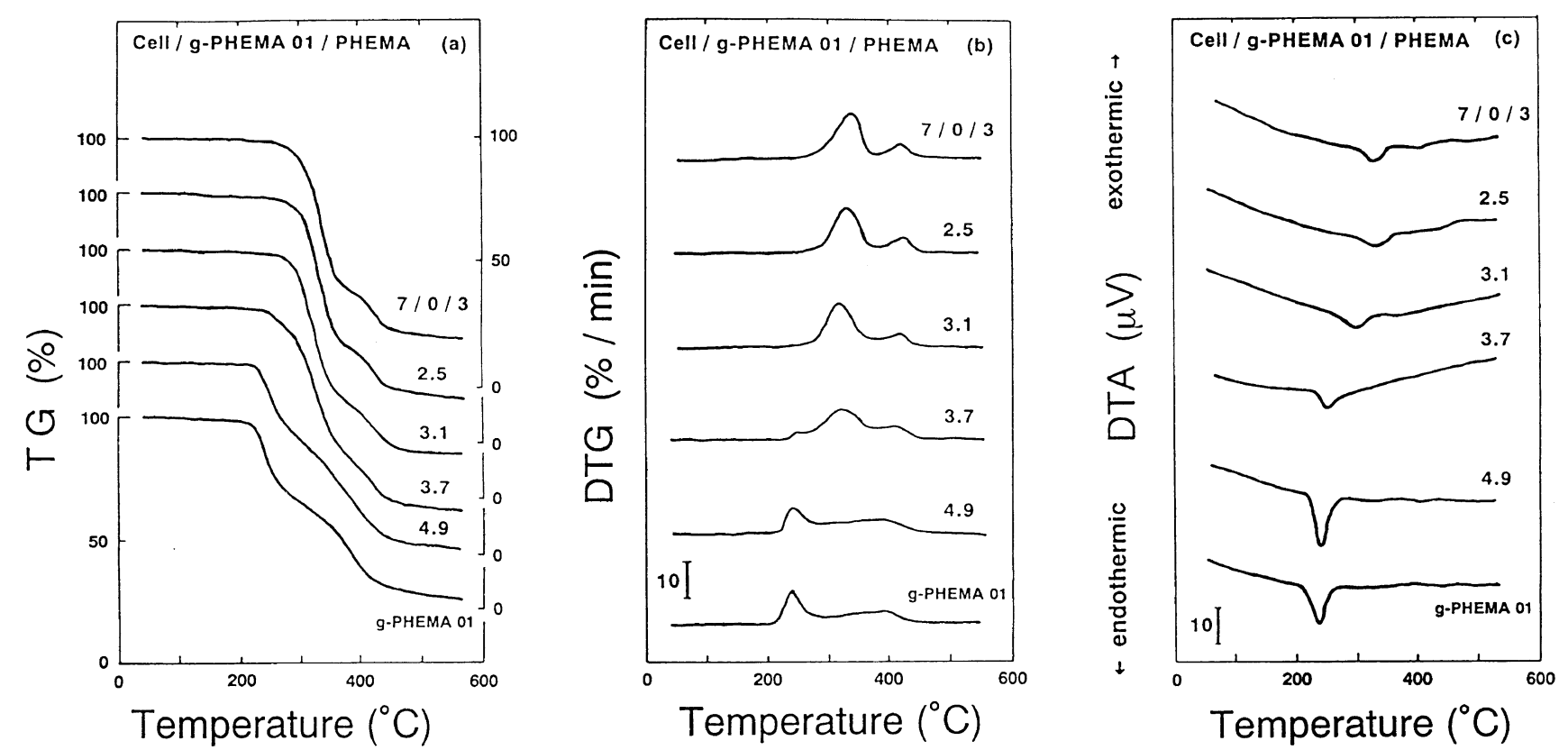

Figure 1. Thermograms of grafted product (g-PHEMA01) and Cell/PHEMA (7/3) blends containing g-PHEMA01: (a) thermogravimetric (TG) curves; (b) derivative thermogravimetric (DTG) curves; (c) differential thermal analysis (DTA) curves.

A SEIKO SDM5600H with a DMS200 module was used for dynamic mechanical measurements from -100 to $300^{\circ} \mathrm{C}$ at a frequency of $10 \mathrm{~Hz}$, at a heating rate of $2^{\circ} \mathrm{Cmin}^{-1}$. The samples $\left(\mathrm{ca} .30 \times 6 \times 0.02 \mathrm{~mm}^{3}\right)$ were dried at about $40^{\circ} \mathrm{C}$ under reduced pressure for more than $24 \mathrm{~h}$ prior to measurement.

The samples $\left(\mathrm{ca} .5 \times 5 \times 0.02 \mathrm{~mm}^{3}\right)$ for accessibility measurement ${ }^{17}$ were dried over $\mathrm{P}_{2} \mathrm{O}_{5}$ under reduced pressure for $24 \mathrm{~h}$ at room temperature, immersed in $\mathrm{D}_{2} \mathrm{O}$ for $4 \mathrm{~h}$, and dried again under reduced pressure for $24 \mathrm{~h}$. Infrared spectra were measured with a JASCO FT/IR-300 spectrometer by placing the samples between $\mathrm{NaCl}$ plates with hexachlorobutadiene.

Differential scanning calorimetry (DSC) was carried out with a SEIKO SSC/560S DSC apparatus. The samples $(\mathrm{ca} .20 \mathrm{mg})$ were heated from -50 to $200^{\circ} \mathrm{C}$ at a rate of $20^{\circ} \mathrm{C} \mathrm{min}^{-1}$.

\section{RESULTS AND DISCUSSION}

Figure 1(a) indicates the thermogravimetric (TG) curves of the grafted product (g-PHEMA01) and Cell/PHEMA ( $7 / 3$ by weight) blends containing different amounts of g-PHEMA01. The weight of the Cell $/ \mathrm{g}$ PHEMA01/PHEMA (7/0/3) blend without g-PHEMA01 decreases by $60 \%$ at around $300^{\circ} \mathrm{C}$ and then $20 \%$ at around $400^{\circ} \mathrm{C}$, indicating the presence of different

Polym. J., Vol. 31, No. 12, 1999 thermal decomposition processes. As indicated previously, ${ }^{1,2}$ the decomposition at lower and higher temperatures resulted mainly from that of cellulose and PHEMA, respectively. The thermal decomposition behavior of the $(7 / 2.5 / 3)$ blend containing 2.5 parts of g-PHEMA01 is similar to that of the $(7 / 0 / 3)$ blend. However, the decomposition of the $(7 / 3.7 / 3)$ blend takes place gradually from around $250^{\circ} \mathrm{C}$. The weight of g-PHEMA01 decreases sharply by $25 \%$ at around $220^{\circ} \mathrm{C}$ and then gradually $45 \%$ at around 300 to $400^{\circ} \mathrm{C}$.

The derivative thermogravimetric (DTG) curves in Figure 1(b) illustrate more clearly differences in thermal decomposition behavior of the samples. The DTG curve of the $(7 / 0 / 3)$ blend has two peaks at 340 and $420^{\circ} \mathrm{C}$. As mentioned above, the peaks at lower and higher temperatures corresponded to the decomposition of cellulose and PHEMA, respectively. We use these peak temperatures as a measure of thermal stability. The peak temperatures of the $(7 / 2.5 / 3)$ blend are almost equal to those of the $(7 / 0 / 3)$ blend. The peak at lower temperatures of the $(7 / 3.7 / 3)$ blend becomes broad and a small hump appears at around $250^{\circ} \mathrm{C}$. The peak at around $340^{\circ} \mathrm{C}$ of the $(7 / 4.9 / 3)$ blend almost disappears and the peak at around $250^{\circ} \mathrm{C}$ becomes predominant. The peak at higher temperatures also shifts gradually to lower temperatures. The DTG curve of g-PHEMA01 shows two peaks at around 240 and $400^{\circ} \mathrm{C}$. The peak at lower temperatures 


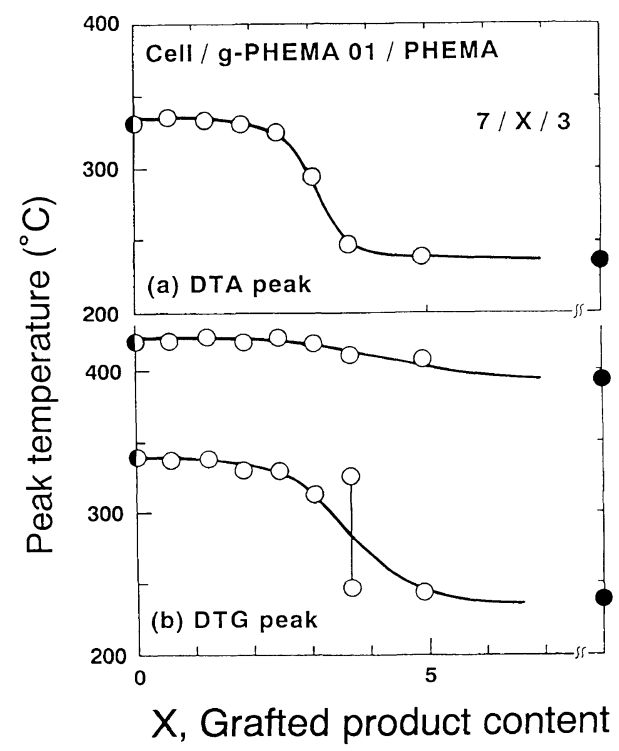

Figure 2. Dependence of DTA and DTG peak temperatures for Cell/PHEMA (7/3) blends containing g-PHEMA01 on grafted product content: (\) Cell/PHEMA (7/3); (@) g-PHEMA01.

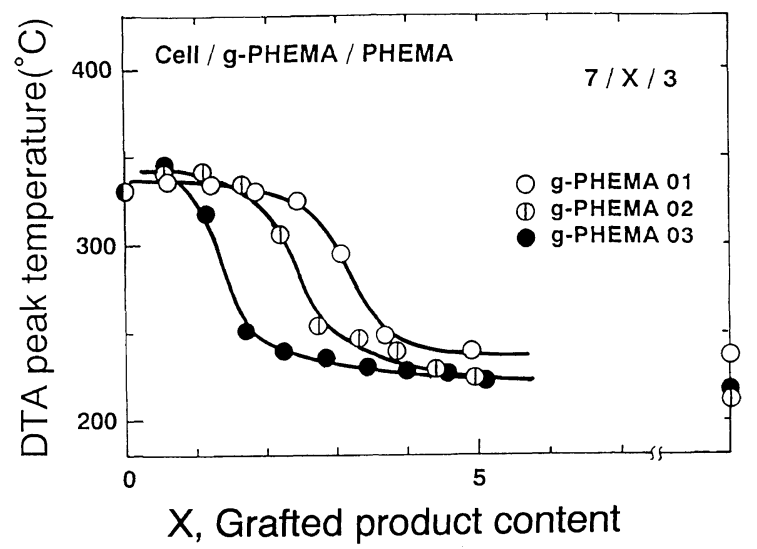

Figure 3. Dependence of DTA peak temperature for Cell/PHEMA $(7 / 3)$ blends containing different grafted products on grafted product content: (1) Cell/PHEMA (7/3).

of g-PHEMA01 is lower by $100^{\circ} \mathrm{C}$ than that of the $(7 / 0 / 3)$ blend, suggesting the pronounced decrease in thermal stability of cellulose.

Figure 1(c) shows the differential thermal analysis (DTA) curves of the same samples. An endothermic peak associated with the decomposition of cellulose is observed, but that of PHEMA is scarcely observed. ${ }^{1,2}$ We can use this peak temperature as a measure of thermal stability. The peak shifts to lower temperatures with the addition of g-PHEMA01, this being consistent with Figure 1(b). It is clear that an increase in g-PHEMA01 content makes the Cell/PHEMA blend, especially cellulose, thermally unstable.

The dependence of the DTA and DTG peak temperatures on grafted product content is revealed in Figure 2. DTA and DTG peak temperatures for cellulose indicate similar dependence on grafted product content. The DTG peak temperature for PHEMA at around $420^{\circ} \mathrm{C}$ also decreases. In our previous work, ${ }^{6-8}$ the decrease in thermal stability of synthetic polymers was hardly observed. The decrease in thermal stability of PHEMA will be the influence of hydroxyl groups in

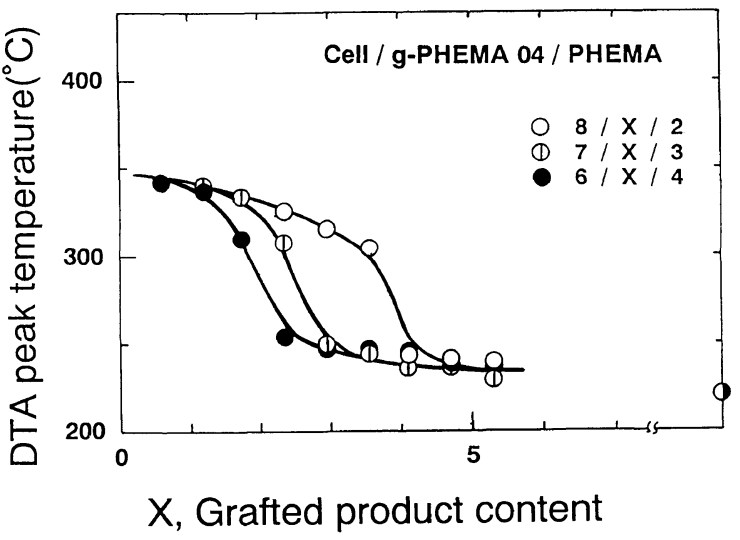

Figure 4. Dependence of DTA peak temperature for the Cell/PHEMA blends with different compositions on the g-PHEMA04 content: (๑) g-PHEMA04.

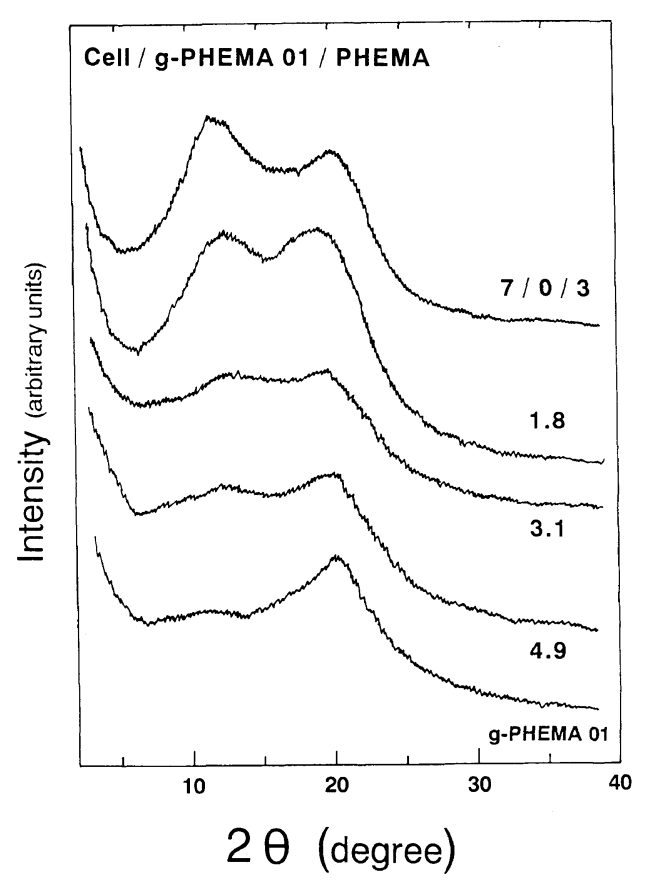

Figure 5. X-Ray diffraction patterns of g-PHEMA01 and Cell/ PHEMA (7/3) blends containing g-PHEMA01.

\section{PHEMA.}

Three grafted products were added to the Cell/PHEMA (7/3) blend. The dependence of the DTA peak temperature on the grafted product content is shown in Figure 3. The grafted product content required to reduce the thermal stability of the Cell/PHEMA (7/3) blend depends on the grafted products. The addition of g-PHEMA03 is most effective of three grafted products. As characterized in Table I, the graft copolymer content in g-PHEMA03 is highest of three grafted products.

The amounts of g-PHEMA04 required to influence the thermal stability of the Cell/PHEMA blends with different compositions are compared in Figure 4. The Cell/PHEMA (6/4) blend is most sensitive to the addition of g-PHEMA04. It is of interest to note that the grafted product content affecting the thermal stability of the Cell/PHEMA blends depends on the grafted product and Cell/PHEMA composition. It should be noted that mainly the thermal stability of cellulose in the blends is influenced. 

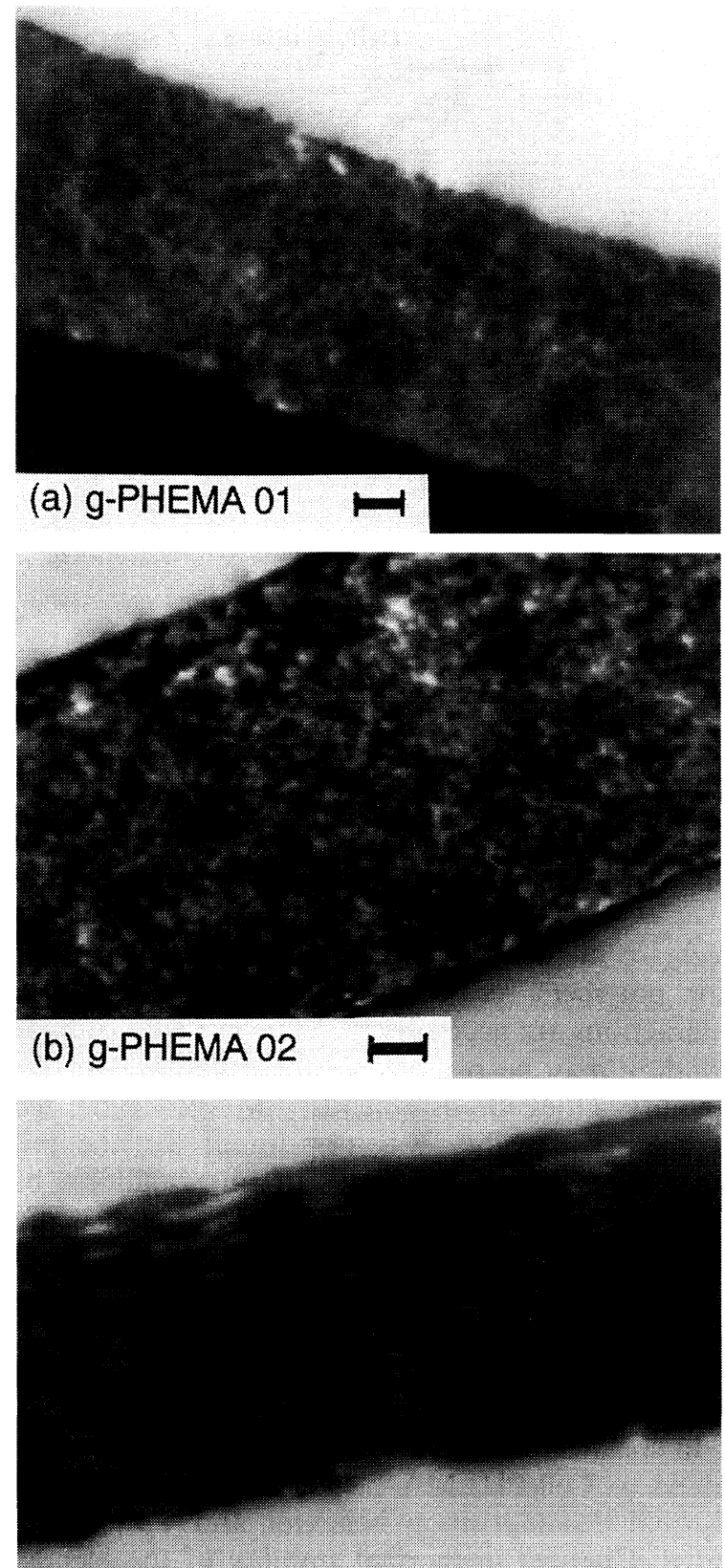

(c) $7 / 0 / 3$
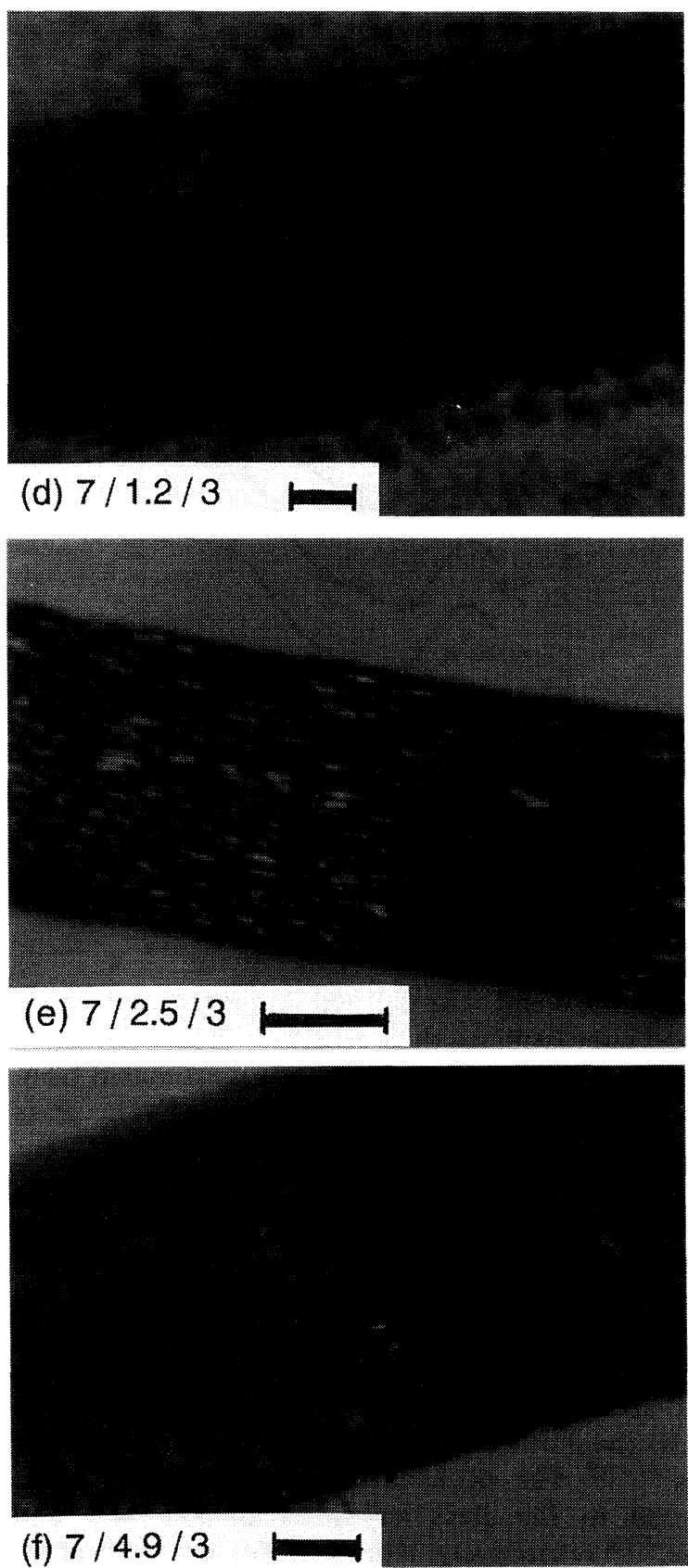

Figure 6. TEM micrographs of grafted products and Cell/PHEMA (7/3) blends containing g-PHEMA01. Scale bar represents $2 \mu \mathrm{m}$ :

Figure 5 indicates the X-ray diffraction patterns of g-PHEMA01 and Cell/PHEMA (7/3) blends containing g-PHEMA01. The peak intensity of the blends decreases with an increase in g-PHEMA01 content, suggesting a decrease in crystallinity. Thermal stability of cellulose mainly depends on crystallinity. ${ }^{18-20}$ PHEMA chains may hinder the crystallization of cellulose chains, leading to lower thermal stability. Accessibility measurement by deuteration $^{17}$ was performed for these blends. Accessibility is defined as the ratio of the number of hydroxyl groups reacted with $\mathrm{D}_{2} \mathrm{O}$ to that of total hydroxyl groups. Accessibility is a measure of crystallinity of cellulose. ${ }^{21-23}$ Accessibility, however, hardly depended on the grafted product content, being the influence of hydroxyl groups in PHEMA.

Figure 6 shows TEM micrographs of g-PHEMA01, g-PHEMA02, and Cell/PHEMA (7/3) blends containing
g-PHEMA01. The dark domains indicate the cellulose phases stained with osmic acid. The microphaseseparated structures of the grafted products are very fine and interfaces between cellulose and PHEMA domains are not clear, indicating good compatibility of cellulose with PHEMA. In the blends, ellipsoidal white domains are dispersed in the dark matrix. The white domains in the $(7 / 0 / 3)$ blend are relatively large, those in the $(7 / 1.2 / 3)$ blend are small, those in the $(7 / 2.5 / 3)$ blend become smaller, and those in the $(7 / 4.9 / 3)$ blend are faint. Changes in microphase-separated structures with the addition of g-PHEMA01 are obvious. A comparison of TEM micrographs with thermal decomposition behavior indicates that the thermal stability of the blends with fine microphase-separated structures decreases. The fine microphase-separated structure and low diffraction intensity imply good compatibility of cellulose with 


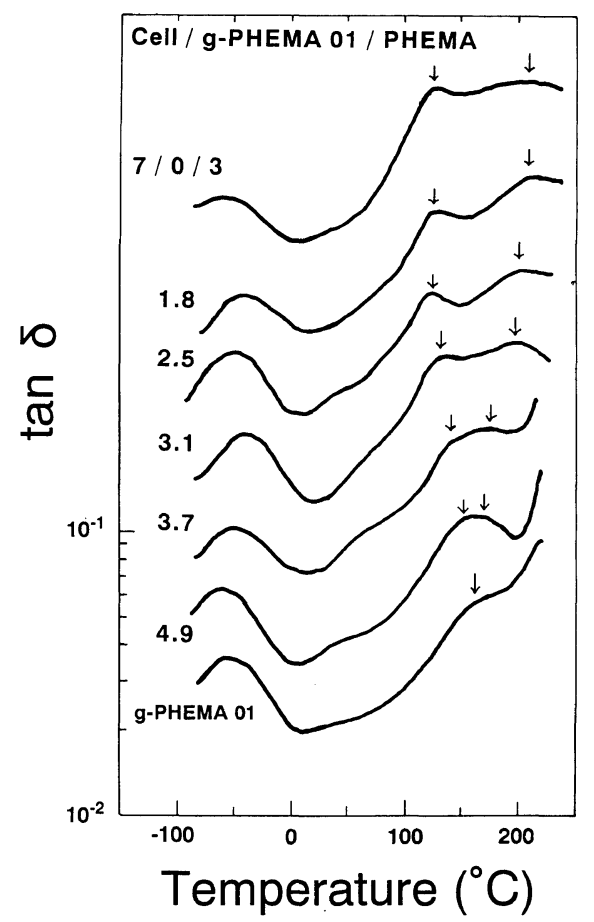

Figure 7. Temperature dependence of mechanical loss tangent for Cell/PHEMA (7/3) blends containing g-PHEMA01.

PHEMA in the blend. The thermal stability of the blends with good compatibility thus decreases markedly.

The compatibility in polymer blends is estimated from $T_{\mathrm{g}}{ }^{3-5}$ DSC measurements were performed. The glass transition at lower temperatures around $120^{\circ} \mathrm{C}$ for PHEMA was obvious, but that at higher temperatures for cellulose was not clear. A similar difficulty in determining $T_{\mathrm{g}}$ by DSC for cellulosic blends has been reported. ${ }^{1,6-8,24-28}$ Figure 7 indicates the temperature dependence of the mechanical loss tangent for the Cell/PHEMA (7/3) blends containing g-PHEMA01. The peak at around $-50^{\circ} \mathrm{C}$ is assigned to the relaxation caused by the motion of methylol groups in the glucose residues. ${ }^{29-32}$ The peaks at around 120 and $200^{\circ} \mathrm{C}$ correspond to the glass transition of PHEMA and cellulose, ${ }^{8,28}$ respectively. The peak for cellulose shifts gradually to lower temperatures with an increase in g-PHEMA01 content, but that for PHEMA shifts to higher temperatures, indicating the influence on the molecular motion of both polymer chains.

The dependence of the mechanical loss tangent and loss modulus peak temperatures on the grafted product content is revealed in Figure 8. Three grafted products were added to Cell/PHEMA (7/3) blend. Both peak temperatures for cellulose decrease with an increase in grafted product content, but those for PHEMA increase. The molecular motion of both polymer chains is influenced by the addition of grafted product. A comparison of Figure 8 with Figures 2 and 3 indicates the changes in both peak temperatures to correspond to those in DTG and DTA peak temperatures. Thus, we can correlate the change in thermal stability of the blends to that in compatibility.

Several miscible cellulosic blends have been reported. ${ }^{24-27,33}$ The thermal decomposition behavior of these blends was investigated. ${ }^{34}$ One blend indicated a

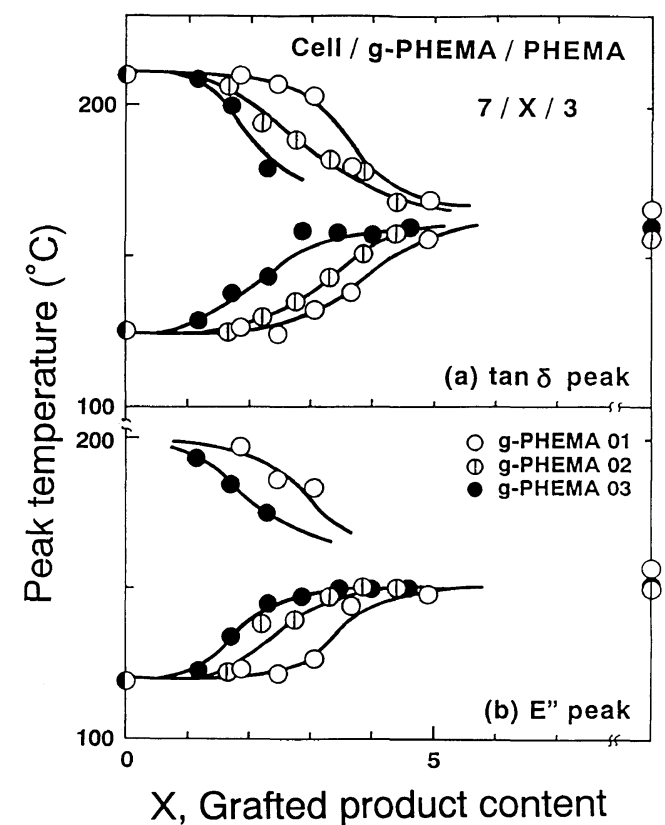

Figure 8. Dependence of mechanical loss tangent and lose modulus peak temperatures for Cell/PHEMA ( $7 / 3)$ blends containing different grafted products on grafted product content: $(D)$ Cell/PHEMA (7/3).

decrease in thermal stability but other blends did not. For polymers to be miscible, specific intermolecular interactions are necessary. ${ }^{3-5}$ The presence of hydrogen bonding may be responsible for differences in thermal stability of the cellulosic blends. ${ }^{33}$ Moreover, the decrease in thermal stability was not found for the miscible amorphous polymer blend. ${ }^{1}$ In our cellulosic blends, compatibilization is induced by the presence of graft copolymers, i.e., compatibilizers. The coexisting synthetic polymer chains are considered to hinder the crystallization of cellulose chains. The compatibility estimation by thermogravimetry thus may be a characteristic method for cellulosic blends containing compatibilizers.

In conclusion, HEMA grafted cellulose products were added to Cell/PHEMA blends as compatibilizers. The thermal decomposition behavior and $T_{\mathrm{g}}$ were investigated. Changes in thermal stability of the blends were correlated to compatibility. It was found that thermogravimetry serves as one of the compatibility estimation methods in cellulosic blends containing grafted products.

\section{REFERENCES}

1. N. Nishioka, H. Ono, and M. Karasuno, Polym. J., 24, 301 (1992).

2. N. Nishioka and N. Yoshida, Polym. J., 24, 1009 (1992).

3. D. R. Paul and S. Newman, Ed., "Polymer Blends," Academic Press, New York, N.Y., 1978.

4. O. Olabisi, L. M. Robeson, and M. T. Schaw, "Polymer-Polymer Miscibility," Academic Press, New York, N.Y., 1979.

5. L. A. Utracki, "Polymer Alloys and Blends," Carl Hanser Verlag, Munich, FRG, 1989.

6. N. Nishioka, M. Yamaoka, H. Haneda, K. Kawakami, and M. Uno, Macromolecules, 26, 4694 (1993).

7. N. Nishioka, Y. Nakano, T. Hirota, N. Fujiwara, and M. Uno, J. Appl. Polym. Sci., 59, 1203 (1996).

8. N. Nishioka, M. Tabata, M. Saito, N. Kishigami, M. Iwamoto, and M. Uno, Polym. J., 29, 508 (1997).

9. N. Nishioka and K. Kosai, Polym. J., 13, 1125 (1981).

10. N. Nishioka, K. Matsumoto, and K. Kosai, Polym. J., 15, 153 (1983).

11. N. Nishioka, K. Minami, and K. Kosai, Polym. J., 15, 591 (1983). 
12. N. Nishioka, Y. Matsumoto, T. Yumen, K. Monmae, and K. Kosai, Polym. J., 18, 323 (1986).

13. S. M. Hudson and J. A. Cuculo, J. Macromol. Sci., Rev. Macromol. Chem., C18, 1 (1980).

14. A. Hebeish and J. T. Guthrie, "The Chemistry and Technology of Cellulosic Copolymers," Springer-Verlag, Berlin-HeidelbergNew York, 1981

15. G. Jayme and P. Kleppe, Papier, 15, 492(1961).

16. R. T. Fort and T. M. Polyzoidis, Eur. Polym. J., 12, 685 (1976).

17. H. Tadokoro, "Structure of Crystalline Polymers," Wiley, New York, N.Y., 1979.

18. L. Reich and S. S. Stivala, "Elements of Polymer Degradation," McGraw-Hill, New York, N.Y., 1971.

19. A. Basch and M. Lewin, J. Polym. Sci., Polym. Chem. Ed., 11, 3071 (1973).

20. M. E. Calahorra, M. Cortázar, J. I. Eguiazábal, and G. M. Guzmán, J. Appl. Polym. Sci., 37, 3305 (1989).

21. J. Mann and H. J. Marrinan, Trans. Faraday Soc., 52, 492 (1956).

22. J. Mann, "Cellulose and Cellulose Derivatives," Vol. V, Part IV, N. M. Bikales and L. Segal, Ed., Wiley, New York, N.Y., 1971, p 89.

23. M. Ioelovitch and M. Gordeev, Acta Polym., 45, 121 (1994).

24. Y. Nishio, S. K. Roy, and R. St. J. Manley, Polymer, 28, 1385 (1987).

25. Y. Nishio and R. St. J. Manley, Macromolecules, 21, 1270 (1988)

26. Y. Nishio, N. Hirose, and T. Takahashi, Polym. J., 21, 347 (1989).

27. Y. Nishio and N. Hirose, Polymer, 33, 1519 (1992).

28. J-F. Masson and R. St. J. Manley, Macromolecules, 24, 6670 (1991).

29. Y. Ishida, M. Yoshino, M. Takayanagi, and F. Irie, J. Appl. Polym. Sci., 1, 227 (1959).

30. M. Kimura and J. Nakano, J. Polym. Sci., Polym. Lett. Ed., 14, 741 (1976).

31. D. J. Crofton and R. A. Pethrick, Polymer, 22, 1048 (1981).

32. D. J. Crofton, D. Mancrieff, and R. A. Pethrick, Polymer, 23, 1605 (1982)

33. J-F. Masson and R. St. J. Manley, Macromolecules, 24, 5914 (1991).

34. N. Nishioka, S. Hamabe, H. Murakami, and T. Kitagawa, $J$. Appl. Polym. Sci., 69, 2133 (1998). 